\title{
Beta-Blockers to Prevent Gastroesophageal Varices in Patients with Cirrhosis
}

\author{
Roberto J. Groszmann, M.D., Guadalupe Garcia-Tsao, M.D., Jaime Bosch, M.D., \\ Norman D. Grace, M.D., Andrew K. Burroughs, M.B., Ch.B., Ramon Planas, M.D., \\ Angels Escorsell, M.D., Juan Carlos Garcia-Pagan, M.D., David Patch, M.B., B.S., \\ Daniel S. Matloff, M.D., Hong Gao, M.D., Ph.D., and Robert Makuch, Ph.D., \\ for the Portal Hypertension Collaborative Group
}

ABSTRACT
From the Veterans Affairs Connecticut Healthcare System, West Haven (R.J.G. G.G.-T.); Yale University School of Medicine, New Haven, Conn. (R.J.G., G.G.-T., H.G., R.M.); Hospital Clinic I Provincial de Barcelona, Barcelona (J.B., A.E., J.C.G.-P.) Brigham and Women's Hospital, Boston (N.D.G.); Faulkner Hospital, Jamaica Plain Mass. (N.D.G., D.S.M.); the Royal Free Hospital and School of Medicine, London (A.K.B., D.P.); and Hospital Germans Trias I Pujol, Badalona, Spain (R.P.). Address reprint requests to Dr. Groszmann at the Yale University School of Medicine, VA C Healthcare System, Digestive Disease Sec tion/111 H, 950 Campbell Ave., West Haven, CT 06516

Drs. Groszmann and Garcia-Tsao contributed equally to the article.

N Engl J Med 2005;353:2254-61. Copyright (c) 2005 Massachusetts Medical Society. 


\section{N}

ONSELECTIVE BETA-ADRENERGIC blockers reduce portal pressure through a reduction in portal venous inflow ${ }^{1,2}$ as a result of a decrease in cardiac output $\left(\beta_{1}\right.$-adrenergic blockade) and splanchnic blood flow $\left(\beta_{2}\right.$-adrenergic blockade). Randomized, controlled trials have demonstrated that nonselective beta-blockers prevent variceal hemorrhage in patients with varices. ${ }^{3}$ Decreasing portal pressure at earlier stages may prevent gastroesophageal varices. In fact, an experimental study demonstrated that beta-blockers prevent the development of portosystemic collateral vessels. ${ }^{4}$ Therefore, we conducted a study to evaluate the efficacy of nonselective beta-blockers in preventing gastroesophageal varices and to assess whether baseline and sequential measurements of the hepatic venous pressure gradient (HVPG) are useful in predicting the development of varices.

\section{METHODS}

The study was an investigator-initiated, randomized, double-blind, placebo-controlled, clinical trial conducted at four sites. The protocol was approved by the institutional review board at each site, and all patients gave written informed consent. Timolol maleate (Blocadren) and placebo were provided by Merck; Merck did not participate in any other aspect of the study, including study design, data analysis, and manuscript preparation.

\section{PATIENTS}

Patients were enrolled between August 1993 and March 1999 and followed until September 2002. Eligible patients had cirrhosis and portal hypertension, as defined by an HVPG of at least $6 \mathrm{~mm} \mathrm{Hg}$; did not have gastroesophageal varices; and were older than 18 years and younger than 75 years of age. The diagnosis of cirrhosis was either biopsyproven or clinically suspected and confirmed by the finding of an HVPG of $10 \mathrm{~mm} \mathrm{Hg}$ or greater. The absence of gastroesophageal varices was determined unanimously at endoscopy by two staff endoscopists who were present during the entire procedure and who evaluated the procedure independently. Exclusion criteria included ascites requiring diuretics, hepatocellular carcinoma, splenic- or portalvein thrombosis, concurrent illnesses expected to decrease life expectancy to less than one year, the use of any drug or procedure affecting splanchnic hemodynamics or portal pressure, primary biliary cirrhosis or primary sclerosing cholangitis, con- traindications to beta-blocker therapy, pregnancy, or alcohol intake during the dose-titration phase.

Of 780 patients screened for varices, 490 (63 percent) had none. Of these 490 patients, 213 (43 percent) were included in the study. The remaining 277 were excluded for the following reasons: $92 \mathrm{de}-$ clined to participate, 79 had concomitant illnesses, 52 had a normal HVPG (less than $6 \mathrm{~mm} \mathrm{Hg}$ ), 21 could not tolerate the lowest dose of timolol, 15 had an HVPG of less than $10 \mathrm{~mm} \mathrm{Hg}$ and non-biopsyproven cirrhosis, 6 were lost to follow-up, 4 were consuming alcohol during the titration phase, 4 were receiving treatment with interferon or phlebotomy, 2 had primary biliary cirrhosis, and in 2 efforts to measure the HVPG were unsuccessful.

\section{TITRATION OF THE DOSE}

The dose of timolol (or placebo) to be used during the study was determined for each patient before randomization during a titration period in which open-label timolol was administered orally. The starting dose of timolol was $5 \mathrm{mg}$ per day and was increased by $5 \mathrm{mg}$ every three days until one of the following occurred: the resting heart rate was reduced by 25 percent from the baseline value, the resting heart rate fell below 55 beats per minute, a daily dose of $80 \mathrm{mg}$ of timolol was reached, or the patient could not tolerate a further increase in the dose.

\section{RAN DOMIZATION}

After the titration period, patients were randomly assigned to receive timolol or an identical-appearing placebo tablet. The randomization code was generated by computer for each participating center. Patients were stratified according to the cause of cirrhosis (alcoholic vs. nonalcoholic) and baseline HVPG (less than $10 \mathrm{~mm}$ Hg vs. $10 \mathrm{~mm}$ Hg or more). An alcoholic cause was defined as a long-standing history of alcohol ingestion exceeding $60 \mathrm{~g}$ per day. In patients with a dual alcoholic and viral cause, the classification of cirrhosis was based on the clinical and histologic findings.

\section{FOLLOW-UP}

Patients were assessed clinically at baseline, one and three months after randomization, and every three months thereafter. At each visit, the heart rate, pill count, occurrence of adverse events, and alcohol consumption were determined and blood was obtained for hematologic and biochemical measurements. To maintain study blinding, the patient's 


\begin{tabular}{|c|c|c|}
\hline Characteristic & $\begin{array}{l}\text { Timolol Group } \\
(\mathrm{N}=108)\end{array}$ & $\begin{array}{l}\text { Placebo Group } \\
\quad(\mathrm{N}=105)\end{array}$ \\
\hline Age $-y r$ & $46 \pm 11$ & $44 \pm 11$ \\
\hline Male sex — no. (\%) & $70(65)$ & $56(53)$ \\
\hline \multicolumn{3}{|l|}{ Race or ethnic group — no. (\%) } \\
\hline White & $100(93)$ & $98(93)$ \\
\hline Black & $3(3)$ & $1(1)$ \\
\hline Latin-American & $3(3)$ & $2(2)$ \\
\hline Indian & $2(2)$ & $3(3)$ \\
\hline Mideastern or Arabian & 0 & $1(1)$ \\
\hline \multicolumn{3}{|l|}{ Cause of cirrhosis - no. (\%) } \\
\hline Alcoholic'† & $26(24)$ & $25(24)$ \\
\hline Nonalcoholic & $82(76)$ & $80(76)$ \\
\hline $\mathrm{HCV}$ & $67(62)$ & $67(64)$ \\
\hline $\mathrm{HBV}$ & $6(6)$ & $2(2)$ \\
\hline Cryptogenic & $5(5)$ & $5(5)$ \\
\hline Other & $4(4)$ & $6(6)$ \\
\hline Anti-HCV positivity - no. (\%) & $70(65)$ & $74(70)$ \\
\hline Child-Pugh score & $5.4 \pm 0.7$ & $5.4 \pm 0.8$ \\
\hline \multicolumn{3}{|l|}{ Child-Pugh class - no. (\%) } \\
\hline A & $98(91)$ & $91(87)$ \\
\hline B & $10(9)$ & $14(13)$ \\
\hline Mean blood pressure $-\mathrm{mm} \mathrm{Hg}$ & $94 \pm 10$ & $93 \pm 12$ \\
\hline Heart rate - beats $/ \mathrm{min}$ & $75 \pm 11$ & $74 \pm 10$ \\
\hline Hemoglobin — g/dl & $13.8 \pm 1.5$ & $13.5 \pm 1.7$ \\
\hline White-cell count $-\times 10^{-3} / \mathrm{mm}^{3}$ & $5.7 \pm 2.8$ & $5.7 \pm 2.1$ \\
\hline Platelet count $-\times 10^{-3} / \mathrm{mm}^{3}$ & $122 \pm 72$ & $119 \pm 46$ \\
\hline Total bilirubin $-\mathrm{mg} / \mathrm{dl}$ & $1.2 \pm 0.7$ & $1.12 \pm 0.8$ \\
\hline Albumin $-\mathrm{g} / \mathrm{dl}$ & $3.9 \pm 0.5$ & $3.9 \pm 0.5$ \\
\hline Prothrombin time - INR & $1.34 \pm 2.53$ & $1.34 \pm 2.52$ \\
\hline Aspartate aminotransferase $-U /$ liter & $93 \pm 74$ & $89 \pm 59$ \\
\hline Alanine aminotransferase $-U /$ liter & $106 \pm 101$ & $105 \pm 96$ \\
\hline Alkaline phosphatase $-U /$ liter & $138 \pm 70$ & $153 \pm 97$ \\
\hline Serum sodium — mmol/iter & $140 \pm 3$ & $140 \pm 4$ \\
\hline Blood urea nitrogen $-\mathrm{mg} / \mathrm{dl}$ & $14 \pm 8$ & $15 \pm 10$ \\
\hline Creatinine $-\mathrm{mg} / \mathrm{dl}$ & $0.9 \pm 0.2$ & $0.9 \pm 0.2$ \\
\hline $\mathrm{HVPG}-\mathrm{mm} \mathrm{Hg}$ & $11.7 \pm 4.3$ & $11.7 \pm 4.1$ \\
\hline HVPG $\geq 10$ mm Hg - no. (\%) & $67(62)$ & $67(64)$ \\
\hline Median follow-up - mo & 52.7 & 57.9 \\
\hline
\end{tabular}

* Plus-minus values are means \pm SD. There were no significant differences between groups. Race or ethnic group was self-reported. To convert values for bilirubin to micromoles per liter, multiply by 17.1. To convert values for blood urea nitrogen to micromoles per liter, multiply by 0.357 . To convert values for creatinine to micromoles per liter, multiply by 88.4 . HCV denotes hepatitis $C$ virus, $\mathrm{HBV}$ hepatitis $\mathrm{B}$ virus, and INR international normalized ratio.

$\uparrow$ The majority ( 37 of 51 [ 73 percent]) had been abstinent from alcohol for more than one month; 5 others had evidence of mild alcoholic hepatitis at randomization ( 2 in the timolol group and 3 in the placebo group).

$\checkmark$ The Child-Pugh score can range from 5 to 15 , with higher scores indicating more severe liver disease. heart rate was measured by the study nurse and not by the investigators. At baseline and every year thereafter, upper endoscopy was performed and HVPG was measured as described elsewhere. ${ }^{5}$ According to standard practice at the time, no patient received antiviral therapy during the study.

\section{END POINTS}

The primary end points were the development of varices or variceal hemorrhage as identified unanimously at endoscopy by two staff endoscopists who were present during the entire procedure and who evaluated the procedure independently. Varices were defined by the presence of one of the following: large varices (at least $5 \mathrm{~mm}$ ); small varices (less than $5 \mathrm{~mm}$ ), confirmed by endoscopy 6 months later; small varices (less than $5 \mathrm{~mm}$ ) on one endoscopy, with the patient's declining to undergo comfirmatory endoscopy or an inability to perform confirmatory endoscopy in the subsequent 12 months; or gastric varices confirmed by endoscopic ultrasonography. Variceal hemorrhage was defined as any hematemesis or melena in a patient in whom endoscopy showed active bleeding from an esophageal or gastric varix, an esophageal or gastric varix with an adherent clot, or varices but no other source of bleeding. In addition, acute, clinically significant bleeding as a result of portal hypertensive gastropathy (defined by the need for a 2-unit transfusion, a 6-point drop in the hematocrit, or a drop of more than $20 \mathrm{~mm} \mathrm{Hg}$ in systolic blood pressure with a change in the patient's posture) was considered a primary end point.

Secondary end points were the development of ascites or encephalopathy, liver transplantation, or death. Data collection was terminated and treatment was considered to have failed when a patient reached the primary end point, underwent liver transplantation, or died.

\section{ADVERSE EVENTS}

An adverse event was any event that required a diagnostic or therapeutic intervention. All adverse events, regardless of their possible association with the disease or study treatment, were recorded. An adverse event was judged severe if it was considered to endanger the health or safety of the patient.

\section{DATA AND SAFETY MONITORING BOARD}

Members of a data and safety monitoring board were appointed by the National Institute of Diabetes and Digestive and Kidney Diseases and met ev- 
ery six months to review the progress of the study and accumulated data. According to the protocol, one interim analysis was performed on October 26, 2000, after all patients had been enrolled. At that time, the data and safety monitoring board was empowered to recommend termination of the study on the basis of concern about safety or in the presence of sufficient evidence to indicate that timolol was statistically superior to placebo. The board voted unanimously to recommend continuation of the trial.

\section{STATISTICAL ANALYSIS}

We estimated that treatment with timolol would reduce the four-year cumulative probability of varices from 50 percent (the rate without treatment) ${ }^{6,7}$ to 30 percent, given a statistical power of 80 percent to detect an absolute difference of 20 percent between the placebo and timolol groups at a two-sided alpha level of 0.05 . We estimated that the study would require 193 patients, and we then increased this amount by 10 percent to account for the loss of patients to follow-up, yielding a total of $212 \mathrm{pa-}$ tients.

All analyses were conducted according to the intention-to-treat principle. Qualitative variables were compared by means of Fisher's exact test. Wilcoxon's rank-sum test was used to compare continuous variables or ordinal data. Actuarial probabilities were calculated according to the KaplanMeier method and compared with use of the logrank test. Data were censored when the primary end point was reached, at the time of transplantation or death, or at the time of the last visit, whichever occurred first. A Cox proportional-hazards model was used to identify the variables that best explained the variability in the rates of primary end points, treatment failure, and survival. Calculations were performed with the use of the SAS statistical software package.

\section{RESULTS}

A total of 213 patients underwent randomization: 108 were assigned to receive timolol, and 105 to receive placebo (110 at the Barcelona center, 52 at the Connecticut center, 26 at the London center, and 25 at the Boston center). The median time from screening endoscopy to randomization was 29 days (range, 8 to 105). As shown in Table 1, the baseline characteristics were similar in the two groups. There were no significant differences between groups in the

\begin{tabular}{|c|c|c|c|}
\hline \multirow[t]{2}{*}{ Variable } & $\begin{array}{l}\text { Timolol Group } \\
\quad(N=108)\end{array}$ & $\begin{array}{l}\text { Placebo Group } \\
\qquad(\mathrm{N}=105)\end{array}$ & $\begin{array}{c}P \\
\text { Value }\end{array}$ \\
\hline & \multicolumn{2}{|c|}{ no./total no. (\%) } & \\
\hline Primary end point* & $42 / 108(39)$ & $42 / 105(40)$ & 0.89 \\
\hline Large varices & 4 & 4 & \\
\hline Confirmed small varices & 27 & 30 & \\
\hline Unconfirmed small varices & 8 & 5 & \\
\hline Variceal hemorrhage & 2 & 3 & \\
\hline $\begin{array}{l}\text { Hemorrhage from portal hyper- } \\
\text { tensive gastropathy }\end{array}$ & 1 & 0 & \\
\hline Secondary end point ${ }^{\dagger}$ & $22 / 66(33)$ & $22 / 63(35)$ & 1.00 \\
\hline Ascites & 4 & 6 & \\
\hline Death & 3 & 2 & \\
\hline Hepatic encephalopathy & 3 & 2 & \\
\hline Transplantation & 1 & 0 & \\
\hline Death & 0 & 1 & \\
\hline Ascites and encephalopathy & 6 & 5 & \\
\hline Transplantation & 1 & 0 & \\
\hline Death & 5 & 5 & \\
\hline Transplantation & $7 \dagger$ & $2 \sqrt{ }$ & \\
\hline Death & 109 & $15 \|$ & \\
\hline Treatment failure & $59 / 108(55)$ & $59 / 105(56)$ & 0.89 \\
\hline
\end{tabular}

* No patient had isolated gastric varices as a primary end point. Among the patients in whom esophageal varices developed, five (four in the timolol group and one in the placebo group) had concomitant gastric varices (three had junctional and two had fundal varices).

$\dagger$ The total number in each group reflects the number of patients who did not reach a primary end point (66 in the timolol group and 63 in the placebo group).

$¥$ The reasons for transplantation were hepatocellular carcinoma in four patients, decompensated cirrhosis in two patients, and acute-on-chronic liver failure in one patient

$\int$ In both patients, the reason for transplantation was hepatocellular carcinoma.

I Four deaths were related to infection followed by renal or liver dysfunction, one was due to hepatocellular carcinoma, and five were unrelated to liver disease. Ascites, encephalopathy, or both developed in 8 of the 10 patients who died.

|| Six deaths were related to infection followed by renal dysfunction, three were due to hepatocellular carcinoma, two were due to liver failure, and four were unrelated to liver disease. Ascites, encephalopathy, or both developed in 8 of the 15 patients who died.

** Treatment failure was defined by the occurrence of the primary end point (varices and variceal hemorrhage), transplantation, or death.

proportion of patients with alcohol-induced cirrhosis or in the HVPG. The median Child-Pugh score was 5 (range, 5 to 9 ; scores can range from 5 to 15 , with higher scores indicating more severe liver disease). The median HVPG was $11 \mathrm{~mm} \mathrm{Hg}$ (range, 6 to 25), with 63 percent of the patients having an HVPG of at least $10 \mathrm{~mm} \mathrm{Hg}$. The median duration of follow-up was 54.9 months (range, 0 to 99.4).

The median daily dose of timolol was $10.8 \mathrm{mg}$ 
(range, 1.25 to 80.0) in the timolol group, and the median daily dose of the timolol placebo was $12.9 \mathrm{mg}$ (range, 1.25 to 80.0 ) in the placebo group (according to titration). The dose had to be reduced in 29 patients (26 in the timolol group vs. 3 in the placebo group, $\mathrm{P}<0.001)$, and the study medication was withdrawn prematurely in 46 patients ( 25 in the timolol group vs. 21 in the placebo group, $\mathrm{P}=0.62$ ).

Adherence to treatment was considered adequate if the pill count showed more than 70 percent adherence; this degree of adherence was achieved in 86 patients in the timolol group (80 percent) and 88 patients in the placebo group (84 percent).

\section{END POINTS}

The rates of the primary and secondary end points and treatment failure are shown in Table 2. A total of 84 patients reached the primary end point of varices or variceal bleeding: 42 of 108 patients in the timolol group and 42 of 105 patients in the placebo group (39 percent vs. 40 percent, $\mathrm{P}=0.89$ ) (Table 2 and Fig. 1). The rates of the primary end point (both overall and for the timolol group) did not differ significantly when patients who had a reduction in the dose or stopped treatment were compared with those who did not have a reduction in the dose or discontinue treatment (data not shown). Hepatocellular carcinoma, which was not considered an end point of the study, occurred in eight patients in the timolol group and six patients in the placebo group.

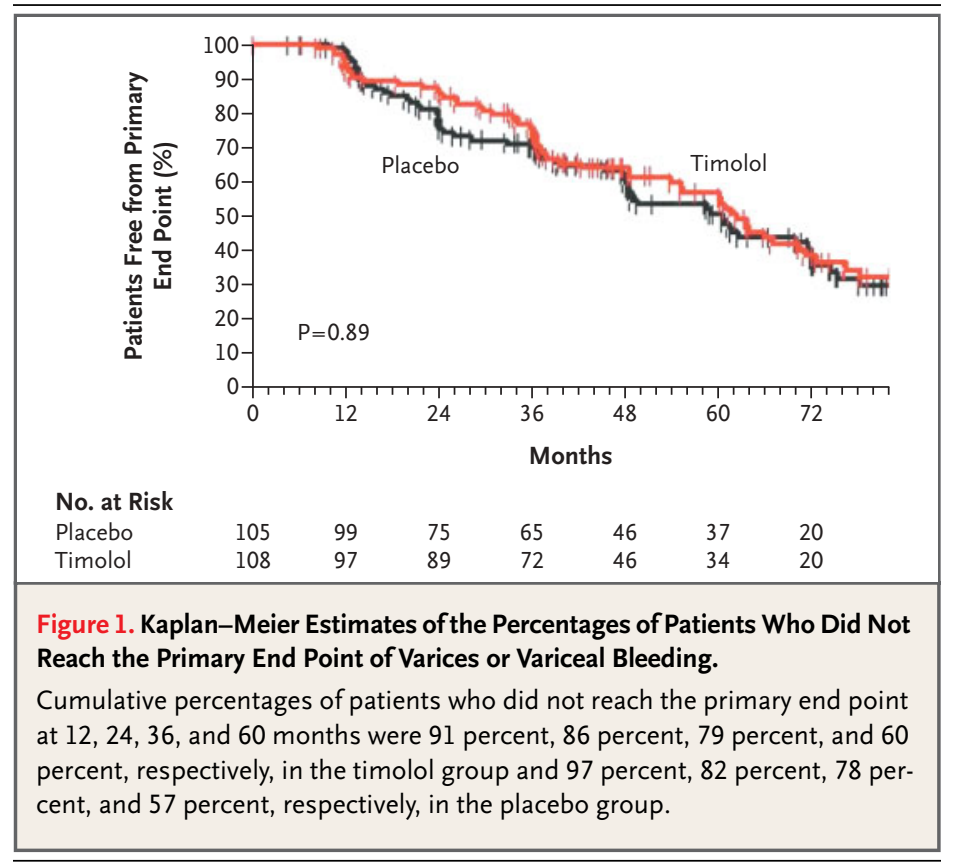

A comparison of the 84 patients who reached the primary end point with the 129 patients who did not reach the primary end point revealed that the following baseline variables differed at a P value of less than 0.1: the Child-Pugh score, the white-cell count, the aspartate aminotransferase level, the alanine aminotransferase level, and the HVPG. On Cox regression analysis, a baseline HVPG of $10 \mathrm{~mm} \mathrm{Hg}$ or more $(\mathrm{P}=0.005)$ and an elevated aspartate aminotransferase level $(\mathrm{P}=0.007)$ were independently predictive of reaching the primary end point.

\section{ADVERSE EVENTS}

The incidence of moderate or severe adverse events was higher in the timolol group than in the placebo group (48 percent [52 patients] vs. 32 percent [34 patients], $\mathrm{P}=0.02)$. Serious adverse events considered probably related to study medication occurred in 20 patients (18 percent) in the timolol group (7 had bradycardia, as defined by a heart rate of less than 50 beats per minute; 5 had severe fatigue; 4 had wheezing or shortness of breath, 2 had syncope; and 1 each had intermittent claudication and impotence) and in 6 patients ( 6 percent) in the placebo group (1 each had impotence, hypotension, depression, heart failure, nodal rhythm, and bronchospasm) $(\mathrm{P}=0.006)$. None of the complications were fatal.

\section{HEMODYNAMICS}

Except at baseline, the heart rate was significantly lower in the timolol group than in the placebo group throughout the study (Fig. 2A). The average reduction in the heart rate from baseline was 17 percent in the timolol group. Conversely, the HVPG did not differ significantly between groups during the study (Fig. 2B).

At baseline, an HVPG of $10 \mathrm{~mm}$ Hg or more was associated with a significantly higher incidence of the primary end point, as shown in Figure 3A. HVPG measurements were repeated at one year in 154 patients (72 in the timolol group and 82 in the placebo group). As compared with baseline values, the HVPG decreased by a median of $1.45 \mathrm{~mm} \mathrm{Hg}$ among patients in the timolol group, as compared with a decrease of only $0.5 \mathrm{~mm} \mathrm{Hg}$ among patients in the placebo group $(\mathrm{P}=0.07)$; the decrease in the latter group was due solely to a drop in wedge pressure. Reductions in the HVPG of more than 10 percent (Fig. 3B), more than 15 percent, and more than 20 percent were all associated with a significantly lower incidence of the primary end point. More important, a decrease in the HVPG of more 
than 10 percent, more than 15 percent, or more than 20 percent from baseline occurred more frequently in the timolol group ( 53 percent, 43 percent, and 33 percent, respectively) than in the placebo group (38 percent, 24 percent, and 19 percent, respectively), and these differences were significant $(\mathrm{P}=0.04, \mathrm{P}=0.01$, and $\mathrm{P}=0.04$, respectively). Conversely, an increase in the HVPG by more than 10 percent also correlated with an increased likelihood of reaching the end point (Fig. 3C). However, there were no significant differences between groups in the increases in HVPG.

\section{I SCUSSION}

In this placebo-controlled study, treatment with a nonselective beta-blocker, timolol, did not prevent gastroesophageal varices in unselected patients with cirrhosis and portal hypertension and was associated with an increased number of adverse effects. A previous French study of the prevention of varices showed that, in patients without varices or with small varices, the development of large varices was more frequent among propranolol-treated patients than among patients who received placebo. Most of the patients had small varices, and significant differences were confined to this subgroup of patients. ${ }^{8}$ In contrast, a placebo-controlled study that consisted of patients with small varices found a lower rate of variceal enlargement in patients treated with nadolol. ${ }^{9}$

We used timolol, a potent nonselective betablocker, ${ }^{10}$ and as shown in patients with essential hypertension, ${ }^{11}$ once-daily dosing was sufficient to maintain the reduction in heart rate for at least 24 hours. Moreover, the fact that timolol has a higher affinity for both $\beta_{1}$ - and, particularly, $\beta_{2}$-adrenergic receptors than do propranolol and nadolol ${ }^{10,12}$ is important, since $\beta_{2}$-adrenergic-receptor blockade is an important target in the reduction of portal pressure. ${ }^{2}$ In a study of acute effects, timolol decreased HVPG as effectively as did propranolol or nadolol. ${ }^{13}$ However, there are differences in the acute and chronic portal-pressure-reducing effects of beta-blockers, ${ }^{14,15}$ which have been ascribed to differences in receptor blockade $\left(\beta_{1}\right.$-adrenergic receptors are involved in the acute effect and $\beta_{2}$-adrenergic receptors in the chronic effect). ${ }^{15}$ Our negative results may have been partially due to the inclusion of patients with an early stage of cirrhosis and thus a milder splanchnic and systemic hyperdynamic circulatory state, a major factor in the maintenance of portal hypertension and the main target of the action of beta-blockers.

The average decrease in heart rate in the timolol group was 17 percent. This reduction is smaller than the range of 20 to 26 percent (median, 24 percent) reported in studies of beta-blockers in the primary prophylaxis of variceal hemorrhage ${ }^{16-24}$ and is probably due to the lower baseline heart rate (median, 73 beats per minute) in our study than in primary-prophylaxis studies of patients with varices (median, 80 beats per minute) ${ }^{9,17-25}$ or secondaryprophylaxis studies of patients with varices (median, 84 beats per minute). ${ }^{26-29}$ However, the absolute heart rate achieved is a better indicator of betablockade than the percent reduction in heart rate, ${ }^{30}$ and the absolute heart rate in our study during timolol therapy (62 beats per minute) was similar

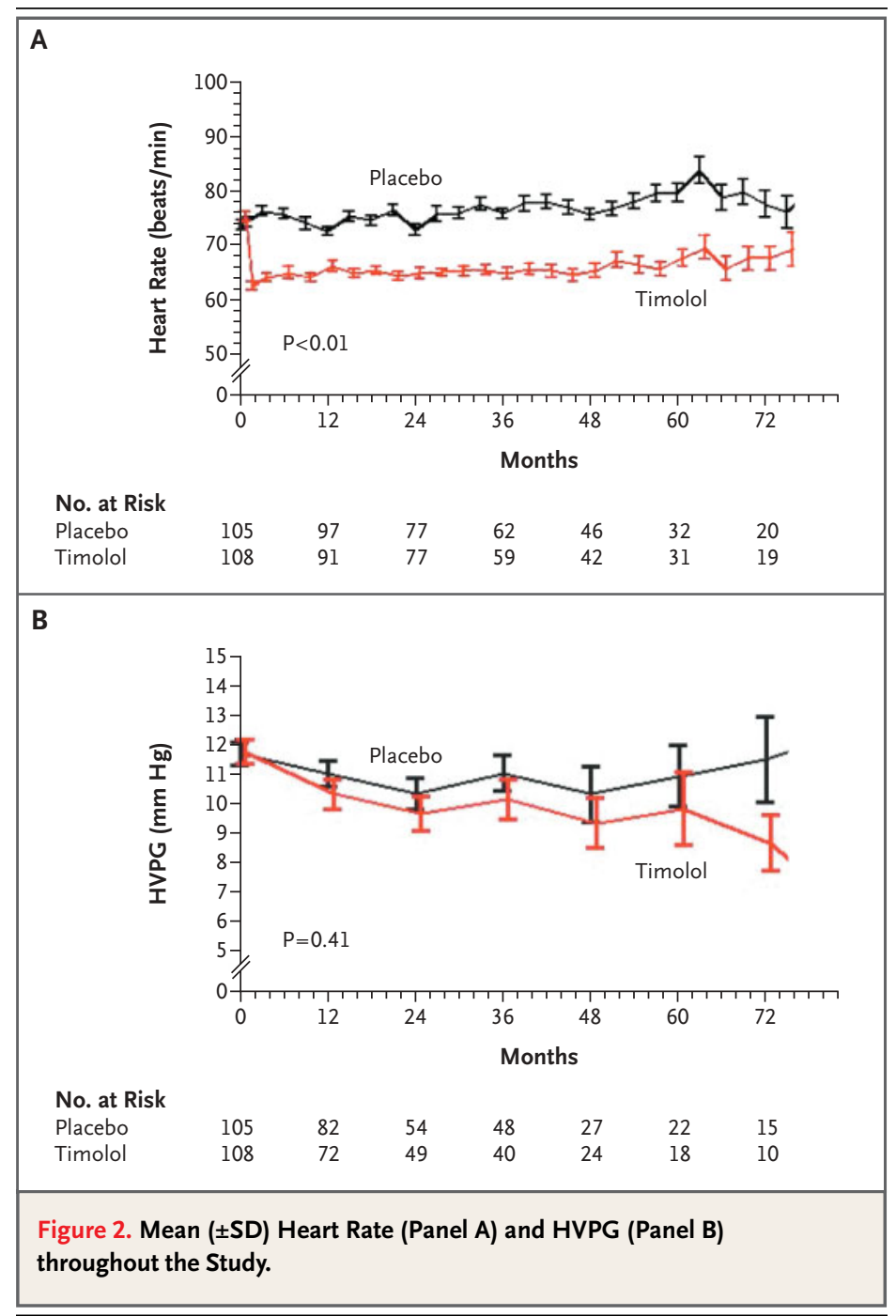




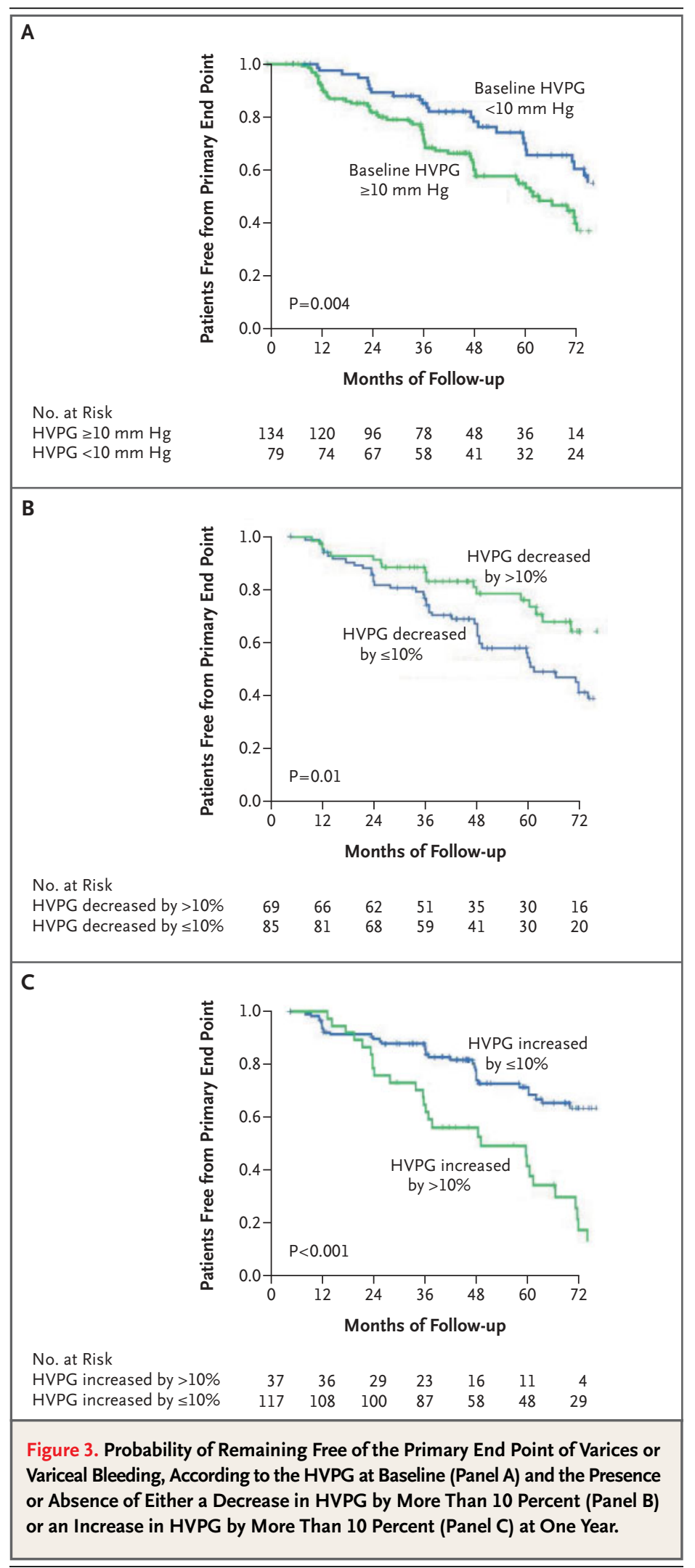

to the median heart rate of 60 beats per minute among patients receiving beta-blockers in previous studies. ${ }^{17-24}$

The lack of an overall significant change in the HVPG may partly explain our negative results. Although it is possible that positive results could have been obtained if the dose of timolol had been higher, drug intolerance limited our ability to increase the dose further in this group of patients with compensated cirrhosis, most of whom were reluctant to tolerate even minimal side effects.

A major finding of our study was the effect of baseline HVPG on outcomes. The rate of the primary end point was significantly lower among patients with a baseline HVPG of less than $10 \mathrm{~mm} \mathrm{Hg}$ than among patients with a baseline HVPG of at least $10 \mathrm{~mm} \mathrm{Hg}$. This finding supports the definition of clinically significant portal hypertension as an HVPG of at least $10 \mathrm{~mm} \mathrm{Hg.}{ }^{31}$ In fact, the baseline HVPG was the strongest independent predictor of the development of varices.

We confirmed the importance of lowering portal pressure shown in previous studies of patients with more advanced cirrhosis. ${ }^{29,32-35}$ We found that reductions in the HVPG of more than 10 percent from baseline were related to a significant decrease in the rate of the primary end point. An important finding was that more patients in the timolol group than in the placebo group had these favorable HVPG responses, indicating that timolol had a beneficial effect, but one that was not sufficient to tip the balance in favor of beta-blockers. Conversely, we also found that increases in portal pressure were associated with the development of varices, although timolol apparently had no ability to prevent this increase in HVPG.

In conclusion, even though the role of nonselective beta-blockers in preventing variceal hemorrhage in patients who already have varices is well established, we found that nonselective betaadrenergic blockers did not prevent varices in patients with cirrhosis and portal hypertension. The use of beta-blockers cannot be widely recommended in this population because of its association with an increased incidence of serious side effects. However, even in this population of patients with compensated cirrhosis, we have confirmed the predictive value of baseline HVPG levels and of a subsequent reduction in the HVPG by more than 10 percent, the latter of which should be the goal in the pharmacologic prevention of gastroesophageal varices. 
Supported by a grant (RO1 46580, to Dr. Groszmann) from the National Institute of Diabetes and Digestive and Kidney Diseases.

We are indebted to the endoscopists, interventional radiologists, pathologists, study coordinators, nurses, and fellows at each of the four participating centers who were part of the Portal Hypertensive Collaborative Group and who contributed to the performance and successful completion of the study; and to A. Blei, A.M. Diehl, A. McCullough, and W. Rand of the external advisory data and safety monitoring board.
REFERENCES

1. Kroeger RJ, Groszmann RJ. Increased portal venous resistance hinders portal pressure reduction during the administration of beta-adrenergic blocking agents in a portal hypertensive model. Hepatology 1985;5:97101.

2. Idem. Effect of selective blockade of beta- 2 adrenergic receptors on portal and systemic hemodynamics in a portal hypertensive rat model. Gastroenterology 1985 ; 88:896-900.

3. D'Amico G, Pagliaro L, Bosch J. Pharmacological treatment of portal hypertension: an evidence-based approach. Semin Liver Dis 1999;19:475-505. [Erratum, Semin Liver Dis 2000;20:399.]

4. Sarin SK, Groszmann RJ, Mosca PG, et al. Propranolol ameliorates the developmen of portal-systemic shunting in a chronic murine schistosomiasis model of portal hy pertension. J Clin Invest 1991;87:1032-6.

5. Groszmann RJ, Wongcharatrawee S. The hepatic venous pressure gradient: anything worth doing should be done right. Hepatology 2004;39:280-3.

6. Christensen E, Fauerholdt L, Schlichting P, Juhl E, Poulsen H, Tygstrup N. As pects of the natural history of gastrointes tinal bleeding in cirrhosis and the effect of prednisolone. Gastroenterology 1981;81: 944-52.

7. Cales $\mathrm{P}$, Desmorat $\mathrm{H}$, Vinel JP, et al. Incidence of large oesophageal varices in patients with cirrhosis: application to prophylaxis of first bleeding. Gut 1990;31:1298302.

8. Cales P, Oberti F, Payen JL, et al. Lack of effect of propranolol in the prevention of large oesophageal varices in patients with cirrhosis: a randomized trial. Eur J Gastroenterol Hepatol 1999;11:741-5.

9. Merkel C, Marin R, Angeli P, et al. A placebo-controlled clinical trial of nadolol in the prophylaxis of growth of small esophageal varices in cirrhosis. Gastroenterology 2004;127:476-84

10. Weiner N. Drugs that inhibit adrenergic nerves and block adrenergic receptors. In Goodman Gilman A, Goodman LS, Gilman A, eds. Goodman and Gilman's the phar macological basis of therapeutics. 6th ed. New York: Macmillan, 1980:176-210.

11. Jennings G, Bobik A, Korner P. Comparison of effectiveness of timolol administered once a day and twice a day in the control of blood pressure in essential hypertension. Med J Aust 1979;2:263-5.

12. Wang T, Kaumann AJ, Brown MJ. (-)Timolol is a more potent antagonist of the positive inotropic effects of (-)-adrenaline than of those of (-)-noradrenaline in human atrium. Br J Clin Pharmacol 1996;42:217-23.
13. Escorsell A, Ferayorni L, Bosch J, et al. The portal pressure response to $\beta$-blockade is greater in cirrhotic patients without varices than in those with varices. Gastroenterology 1997;112:2012-6.

14. Garcia-Tsao G, Grace N, Groszmann $\mathrm{RJ}$, et al. Short term effects of propranolol on portal venous pressure. Hepatology 1986 6:101-6.

15. Merkel C, Bolognesi M, Sacerdoti D, Bombonato G, Cavasin L, Gatta A. Differ ences between acute and chronic effects of nadolol on portal hypertension in patient with cirrhosis: a pathophysiological interpretation. Hepatology 2004;40:Suppl 1 627A. abstract.

6. Pascal JP, Cales P. Propranolol in the prevention of first upper gastrointestinal tract hemorrhage in patients with cirrhosis of the liver and esophageal varices. $\mathrm{N}$ Engl Med 1987;317:856-61. [Erratum, N Engl Med 1988;318:994.]

17. Lebrec D, Poynard T, Capron JP, et al Nadolol for prophylaxis of gastrointestinal bleeding in patients with cirrhosis: a randomized trial. J Hepatol 1988;7:118-25.

18. The Italian Multicenter Project for Propranolol in Prevention of Bleeding. Propranolol prevents first gastrointestinal bleeding in non-ascitic cirrhotic patients: final report of a multicenter randomized trial. J Hepato 1989;9:75-83.

19. Groszmann RJ, Bosch J, Grace ND, et al. Hemodynamic events in a prospective randomized trial of propranolol versus placebo in the prevention of the first variceal hemorrhage. Gastroenterology 1990;99: 1401-7.

20. Angelico M, Carli L, Piat C, Gentile S, Capocaccia L. Effects of isosorbide-5-mononitrate compared with propranolol on firs bleeding and long-term survival in cirrhosis. Gastroenterology 1997;113:1632-9.

21. Borroni G, Salerno F, Cazzaniga M, et al. Nadolol is superior to isosorbide mononitrate for the prevention of the first variceal bleeding in cirrhotic patients with ascites. J Hepatol 2002;37:315-21.

22. Merkel C, Marin R, Enzo E, et al. Randomised trial of nadolol alone or with isosorbide mononitrate for primary prophylaxis of variceal bleeding in cirrhosis. Lance 1996;348:1677-81.

23. Garcia-Pagan JC, Morillas R, Banares R et al. Propranolol plus placebo versus propranolol plus isosorbide-5-mononitrate in the prevention of a first variceal bleed: a double-blind RCT. Hepatology 2003;37: 1260-6.

24. Abecasis R, Kravetz D, Fassio E, et al Nadolol plus spironolactone in the prophy laxis of first variceal bleed in nonascitic cir- rhotic patients: a preliminary study. Hepatology 2003;37:359-65.

25. The PROVA Study Group. Prophylaxis of first hemorrhage from esophageal varices by sclerotherapy, propranolol or both in cirrhotic patients: a randomized multicenter trial. Hepatology 1991;14:1016-24.

26. Sheen IS, Chen TY, Liaw YF. Randomized controlled study of propranolol for the prevention of recurrent esophageal varices bleeding in patients with cirrhosis. Liver 1989;9:1-5.

27. Westaby D, Polson RJ, Gimson AES Hayes PC, Hayllar K, Williams R. A controlled trial of oral propranolol compared with injection sclerotherapy for the longterm management of variceal bleeding. Hepatology 1990;11:353-9.

28. Villanueva C, Balanzo J, Novella MT, et al. Nadolol plus isosorbide mononitrate compared with sclerotherapy for the prevention of variceal rebleeding. $\mathrm{N}$ Engl J Med 1996;334:1624-9.

29. Villanueva C, Minana J, Ortiz J, et al. Endoscopic ligation compared with combined treatment with nadolol and isosorbide mononitrate to prevent recurrent varicea bleeding. N Engl J Med 2001;345:647-55.

30. Ishizaki $\mathrm{T}$, Tawara K. Comparison of disposition and effect of timolol and propranolol on exercise tachycardia. Eur J Clin Pharmacol 1978;14:7-14.

31. D’Amico G, Garcia-Tsao G, Cales P, et al. Diagnosis of portal hypertension: how and when. In: DeFranchis R, ed. Portal Hypertension III: Proceeding of the III Baveno International Consensus Workshop on Definition, Methodology, and Therapeutic Strategies. Oxford, U.K.: Blackwell Science, 2001:36-64. 32. Feu F, Garcia-Pagan JC, Bosch J, et al. Relation between portal pressure response to pharmacotherapy and risk of recurrent variceal haemorrhage in patients with cirrhosis. Lancet 1995;346:1056-9.

33. Abraldes JG, Tarantino I, Turnes J, Garcia-Pagan JC, Rodes J, Bosch J. Hemodynamic response to pharmacological treatment of portal hypertension and long-term prognosis of cirrhosis. Hepatology 2003;37: 902-8.

34. Vorobioff J, Groszmann RJ, Picabea E, et al. Prognostic value of hepatic venous pressure gradient measurements in alcoholic cirrhosis: a 10-year prospective study. Gastroenterology 1996;111:701-9.

35. Aracil C, Lopez-Balaguer JM, Monfort $\mathrm{D}$, et al. Hemodynamic response to betablockers and prediction of clinical efficacy in the primary prophylaxis of variceal bleeding in patients with cirrhosis. Hepatology 2003;38:296A. abstract.

Copyright (c) 2005 Massachusetts Medical Society. 